University of Nebraska - Lincoln

DigitalCommons@University of Nebraska - Lincoln

Management Department Faculty Publications

Management Department

2002

\title{
What a Mess! Participation as a Simple Managerial Rule to "Complexify" Organizations
}

\author{
Donde Ashmos Plowman \\ University of Nebraska-Lincoln, dplowman2@unl.edu \\ Dennis Duchon \\ University of Nebraska-Lincoln, dduchon2@unl.edu \\ Reuben R. McDaniel Jr. \\ University of Texas at Austin, reuben.mcdaniel@mccombs.utexas.edu \\ John W. Huonker \\ Oswego State University, New York, john.huonker@oswego.edu
}

Follow this and additional works at: https://digitalcommons.unl.edu/managementfacpub

Part of the Management Sciences and Quantitative Methods Commons

Plowman, Donde Ashmos; Duchon, Dennis; McDaniel, Reuben R. Jr.; and Huonker, John W., "What a Mess! Participation as a Simple Managerial Rule to "Complexify" Organizations" (2002). Management Department Faculty Publications. 94.

https://digitalcommons.unl.edu/managementfacpub/94

This Article is brought to you for free and open access by the Management Department at DigitalCommons@University of Nebraska - Lincoln. It has been accepted for inclusion in Management Department Faculty Publications by an authorized administrator of DigitalCommons@University of Nebraska - Lincoln. 
Published in Journal of Management Studies, Volume 39, Issue 2 (March 2002), pages 189-206;

doi: 10.1111/1467-6486.00288

Copyright (c) 2002 Blackwell Publishers Ltd. Used by permission.

\title{
What a Mess! Participation as a Simple Managerial Rule to "Complexify" Organizations
}

\author{
Donde P. Ashmos \\ Dennis Duchon \\ The University of Texas at San Antonio \\ Reuben R. McDaniel, Jr \\ The University of Texas at Austin \\ John W. Huonker \\ Oswego State University, New York \\ Corresponding author - Donde P. Ashmos, Department of Management,
} The University of Texas at San Antonio, San Antonio, Texas 78249-0634, USA; dashmos@utsa.edu

\begin{abstract}
This paper adopts a view of organizations as complex adaptive systems and makes a case for making organizations more complex internally through the use of a fairly simple managerial rule-using participative decision making. Participation in decision making enhances connectivity in organizations, which in turn, gives the organization the opportunity to self-organize and co-evolve in more effective ways than when there is minimal connectivity (i.e., autocracy). The paper uses a specific body of research to support the arguments about why participation can benefit the practice of management in modern organizations.
\end{abstract}

\section{Introduction}

We used to think that we knew how to run organizations. Now we know better. More than ever they need to be global and local at the same time, to be small in some ways but big in others, to be centralized some of the time and decentralized most of it. They expect their workers to be both more autonomous and more of a team, their managers to be more delegating and more controlling. (Handy, 1994)

These comments reflect profound changes that are occurring in work organizations; changes that require new modes of organizing and managing. Early conceptualizations of management, developed largely by engineers, relied on a Newtonian view of the world and led to a machine model of organizations. Although the ma- 
chine model of organizations was long ago recognized as unsatisfactory in a rapidly changing world (Burns and Stalker, 1961), it has nonetheless continued to inform the practice of management (Adler, 1999; Daft and Marcic, 1998; Morgan, 1998). In addition to attacks on the machine model from organization theorists, there continue to be efforts by practicing managers to persuade the management community of the inadequacy of the machine model (Hock, 1999; Kelleher, 1997). For example, Dee Hock, founder of VISA, in his book, Birth of the Chaordic Age, encourages managers to move away from organizing by relying on control. In his view the dominance of the machine model assumes people behave as if they were predictable cogs and wheels. He raises this question: "Why do we strive to structure institutions as if they were predictable, controllable machines and labor to mold" (Hock, 1999, p. 23).

The machine model relies on a complex system of highly prescribed rule sets, formalized control, and hierarchical authority structures that are intended, despite their intricacies, to simplify the organization's ongoing operations and lead to simple, well-defined responses, even in the face of shifting environmental conditions. The traditional machine model continues to be attractive precisely because its elaborate rule set is believed to routinize and simplify everyday life in organizations, thereby making operations not only rational but also comprehensible. The rule set of traditional organizations results in "simple" or "streamlined" decision processes involving few decision makers, few informants, a narrow information set, and few interpretations of that information. This "simplified" organization, then, is well positioned for simple, unified responses to its environment. In spite of frequent descriptions of a new age that is full of complexity and paradox, and prescriptions for matching internal variety with external variety (Handy, 1994; Stacey, 1992; Weick, 1979), managers still continue to adhere to the simplifying practices prescribed by the machine model because "the mechanistic mode of thought has shaped our most basic conceptions of what organization is all about" (Morgan, 1998, p. 19). This devotion to the machine model is not a result of its prescriptions working particularly well in a complex world, but because it is not clear exactly what managers can and should do differently.

In this paper we argue what may seem like a paradox. The received wisdom of the machine model advocates the use of elaborate and complex rule systems to create simple processes and simplified (i.e., "sensible") outcomes. In contrast we advocate the use of a "simple" rule system that will generate complex (not simple) processes and potentially complex (not simple) outcomes. We propose that complexity theory can be applied successfully to organizations, and it will suggest management practices very different from those prescribed by machine models. When viewed as complex adaptive systems, organizations benefit from simple rules that may complicate internal functioning but enable more complex responses to environmental shifts. Brown and Eisenhardt (1998) put it this way:

Although the behavior that emerges is complex, the rules that guide it are necessarily simple. In fact, it is their simplicity that creates the freedom to behave in complicated adaptive, and surprising ways. (Brown and Eisenhardt, 1998, p. 18)

We argue that participative decision making is such a simple rule. A straightforward managerial rule of thumb is that there should be widespread participation in organizational decision making. This is a strategic managerial rule that "complexifies" the 
organization and its responses because it draws on and enhances connections within the organization. While the rule is simple, the act of managing participation is not simple. Through decision processes that involve many decision makers, multiple informants, multiple interpretations and a broad set of information, the organization positions itself for developing the more complex responses that may be needed to succeed in a turbulent environment. Complex adaptive systems theory argues, in contrast to the traditional machine model, that complex responses can result from simple rules (Kauffman, 1995). Agents (managers and workers) operating under simple rules (e.g. enhance participation) are capable of complex behavior (effective coevolutionary responses to changing conditions) when they interact frequently, share interpretations and create new meaning for the organization.

The simple rule of enhancing participation in decision making at all levels in the system can make members of the system freer and more autonomous, which in turn can result in the organization considering a broader range of adaptive strategies rather than just the more limited range necessarily constrained by past and current practices. Such a rule will, in some ways, simplify a manager's job by handing off responsibilities to others, but it will also introduce greater complexity into the system itself.

The purpose of this paper is to propose participation as a simple rule that enhances connectivity in organizations. Modern information technology increases our capacity to involve people in organizational processes and increases our ability to enhance connectivity. Participation certainly involves face-to-face interaction, but also involves virtual relationships, as offered through e-mail and other technology. This is different from the more traditional views of participation as a mechanism for enhancing motivation, commitment, or the dissemination of information. We recognize that many value participation as a mechanism enabling these processes (see Locke et al. (1997) for a recent review of participation), but we also contend that participation can do even more. We contend that participation in decision making is also a mechanism for sense-making and knowledge generation, which results from the web of relationships developed and sustained through participation, a web we call "enhanced connectivity." The sense-making and knowledge generation processes developed through enhanced connectivity ultimately creates more complex organizations, but greater complexity also enables self-organizing and potentially quick, effective emergent responses to environmental changes. We offer a description of a stream of research about participation that we have been conducting for several years, which supports our contentions about how a dense web of relationships can contribute to organizational success.

\section{Organizations as Complex Adaptive Systems}

Complexity theory suggests that all organizations are complex adaptive systems that continuously self-organize and co-evolve (Anderson, 1999; Anderson and McDaniel, 2000; Axelrod and Cohen, 1999; Boisot and Child, 1999; Capra, 1996; Handy, 1994; McDaniel, 1997; Stacey, 1995; Wheatley, 1992). This view of organizations, which seems to be reaching acceptance among organization theorists (Anderson, 1999) offers new and useful insights for the practice of management.

Complex adaptive systems gather data about their surroundings, themselves, and their own behavior and then use these data, among other things, for guiding future 
behavior (Kauffman, 1995). The view of organizations as complex adaptive systems emphasizes the importance of connections among parts of the system that enable learning and adaptation (Axelrod and Cohen, 1999; Capra, 1996; Kauffman, 1995). Connections, especially dense, rich connections, transmit information and enable meaning creation among subunits, thus providing systems with improved capacity to learn. This interconnectedness stands in sharp contrast to the barriers to information flow (i.e. "silos") characteristic of the machine model. Connections also provide the system with the capacity to effectively self-organize. Connections enable information flow and meaning creation related to issues that emerge from the connected elements themselves. Complex adaptive systems "self organize," which means that by relying on the web of connections they have the capacity to reconfigure connections and activities. The benefit of self-organizing is an organizational structure that is fluid, yet sensitive to the needs of the connected elements. Connectedness helps system elements to self organize because it enables them to know one other and thus respond by choosing organizing patterns which incorporate that knowledge.

Internal self-organizing can occur because of changes in the system's environment (i.e., changes external to the system) as well as changes in the interrelationships among connected elements. The system has a mutually adaptive relationship with its environment such that both the system and the environment are said to "co-evolve." Co-evolution means that there are changes in the underlying elements of the system, i.e. systems gradually shed elements or connections of the system that may have been useful in the past, and they adopt new elements and patterns of interrelationships that may be useful in the future. Thus, self-organizing can be triggered by an external event, but the self-organizing itself creates a change in the system to which the environment then reacts, and a continuing cycle of mutual learning and adaptation occurs (Kauffman, 1995). The important point is that the system is not simply trying to adapt to a static environment, but rather the system is learning to adapt to an environment that is itself adapting to the system. This notion of co-evolving gives complex systems theory great conceptual power. Also note, however, co-evolution is by no means guaranteed to be mutually successful. The larger environment may shed elements (systems) that do not learn or adapt effectively.

These two properties of complex adaptive systems - self organizing and co-evolution - are central to the argument of using participation as a strategy for "complexifying" the organization. Casti (1995) uses a similar term, "complexification" to describe this phenomenon. We use the more active notion of "complexifying" to signal the potential for managerial intent in the process. Complex adaptive systems are made up of multiple agents, who are unique from each other, but who interact. In the case of organizations these agents are people who, despite the presumed behavioral uniformity imposed by rules, procedures and traditions, are different enough from each, such that each agent's behavior will not be precisely the same in similar conditions. Thus, the conditions exist for "variation" in behavior (Axelrod and Cohen, 1999). These complex organization systems are "orderly enough to ensure stability, yet full of flexibility and surprise" (Kauffman, 1995). Further, these systems are adaptive because they can adjust to changes in the environment, and their behavior is considered emergent because it is not completely determined by the system and can only be partly predicted (Brown and Eisenhardt, 1998; Holland, 1998). Complex systems gather data about their surroundings, themselves, and their own behavior and then transform the data into information by interpret- 
ing it. Interpretation (making sense) and the potential for creating new meaning then guides future behavior (Kauffman, 1995).

Boisot and Child (1999) argue that complex adaptive systems essentially face two broad strategy alternatives when their interpretive process leads them to perceive increased environmental complexity. One alternative is that of complexity reduction. That is, the organization tries to simplify and reduce the amount of data and the number of choices available to its members. Sense-making is undertaken by only a few agents whose roles place them at the top of the hierarchy (and often far from the boundaries where environmental pressures are keenly experienced). This is seen as a way of achieving apparent order in a seemingly complex and disorderly world, and it is the alternative favored by the machine model design (cf. Adler, 1999; Daft and Marcic, 1998; Morgan, 1998). Note that a complexity reduction response is accomplished by emphasizing formal role relationships and thereby minimizing connections, (i.e. minimal participation among agents in the system).

A different alternative, one which is consistent with the characteristics of complex adaptive systems, is a complexity absorption response. Rather than trying to simplify data and choices, this alternative embraces, or internalizes, the complexity of its environment. Such a response means the organization "holds multiple and sometimes conflicting representations of environmental variety, retaining in their behavioral repertoire a range of responses, each of which operates at a lower level of specificity" (Boisot and Child, 1999, p. 238). Robust connectivity via participation in organizations facilitates complexity absorption because many agents are together simultaneously trying to "make sense." That is, many parts of the system (not just the top) are using their view of events, their knowledge of the organization, and their knowledge of themselves in order to discover or create a successful organizational adaptation. Note that while Locke et al. (1997) contend that "... participation is best viewed as a process of information exchange and knowledge transfer" (p. 323), we argue that participation goes even further. Participation facilitates the creation of "meaning," a collective sense of what is real and true. While such a meaning creation effort will seem somewhat "messy" and disorganized when viewed through the lens of the machine model; it in fact allows the organization to consider and experiment with a much larger pool of adaptive behaviors than would be possible if only a few agents (e.g., the top of the hierarchy) were involved. Essentially complexity absorption requires the organization to learn and develop adaptive strategies wholistically, which is only possible because of the web of connections developed through participative processes.

\section{The Need for Enhanced Connectivity}

When organizations are encouraged to recognize connections, when people are encouraged to enhance existing connections and create new connections as seems appropriate to the task, the organization as a whole system is more capable of coevolving effectively with its environment. The probability of the system's successful environmental co-evolution is thereby improved as the quality of internal connections increases.

Successful co-evolution between the system and its environment is more likely because high quality internal connections represent multifaceted, multidimensional re- 
lationships which allow (even demand) organizational members to exchange more than specialized information. These are relationships in which not only all kinds of data and information are in play, but also commentary on the meaning of the data. Ideas, and their unfolding meaning and use will be amplified and expanded as a naturally occurring part of relationships. New ideas will more readily emerge as a consequence of an expanded data set and an expanded range of meaning. New ideas and new possibilities are in turn set loose in the network of connections where they will be subject to re-interpretation and modification and where a collective sense of what actions are needed can continually emerge.

Enhancing connections, however, is potentially problematic for managers who have become accustomed to the search for the stability, predictability, and orderliness the machine-model of organizations promises. Increasing the number and types of connections in the system also increases the potential for conflict in the system. Encouraging connections can subject open systems to confusion, messiness and interagent conflict because connections increase the amount and complexity of information with which the agent must cope. Encouraging connections creates intra-agent conflict because it will require agents to cast aside the assumptions of the machine model that lie at the heart of many organizations; letting go of practices which, even if not entirely satisfactory, are at least familiar and habitual. Managing conflict is difficult but not impossible, and essentially requires developing "rules of engagement" that will permit argumentation and debate but will not permit endangering the network of relationships or threatening the agents' ability or motivation to work together (Eisenhardt et al., 1997). As Eisenhardt et al. (1997, p. 78) point out, managers face the challenge of keeping "constructive conflict from degenerating into dysfunctional interpersonal conflict [and encourages] managers to argue without destroying their ability to work as a team."

\section{Connectivity Makes the System More Complex}

Encouraging connections through participation is essentially an exercise in complexifying everyday life in an organization because it encourages people to enter unknown areas, unfamiliar roles, new patterns. Intentionally complexifying the internal landscape of an organization can have important benefits as well as costs (Ashmos et al., 1996). We argue that intentional internal complexity, which may in fact be initiated by the simple strategic rule of increased participation, can give an organization its best chance for effective co-evolutionary patterns. That is, intentionally complicating an organization internally gives it its best chance for long-term survival.

Figure 1 contrasts the machine model view and complex adaptive systems view of organizations. The intricate rule systems of the machine model minimize connections among agents. Machine model rule systems separate agents one from another, minimize agent participation in decision making, and rely on elaborate control mechanisms to ensure that the agents separated from each other are following the rules. In these systems highly standardized procedures serve as coordinating mechanisms and decision rules for agents operating in a system where each element is tightly controlled. Elaborate rules essentially simplify organizational decision processes because the rule system itself becomes the only active agent in a decision. While other agents 


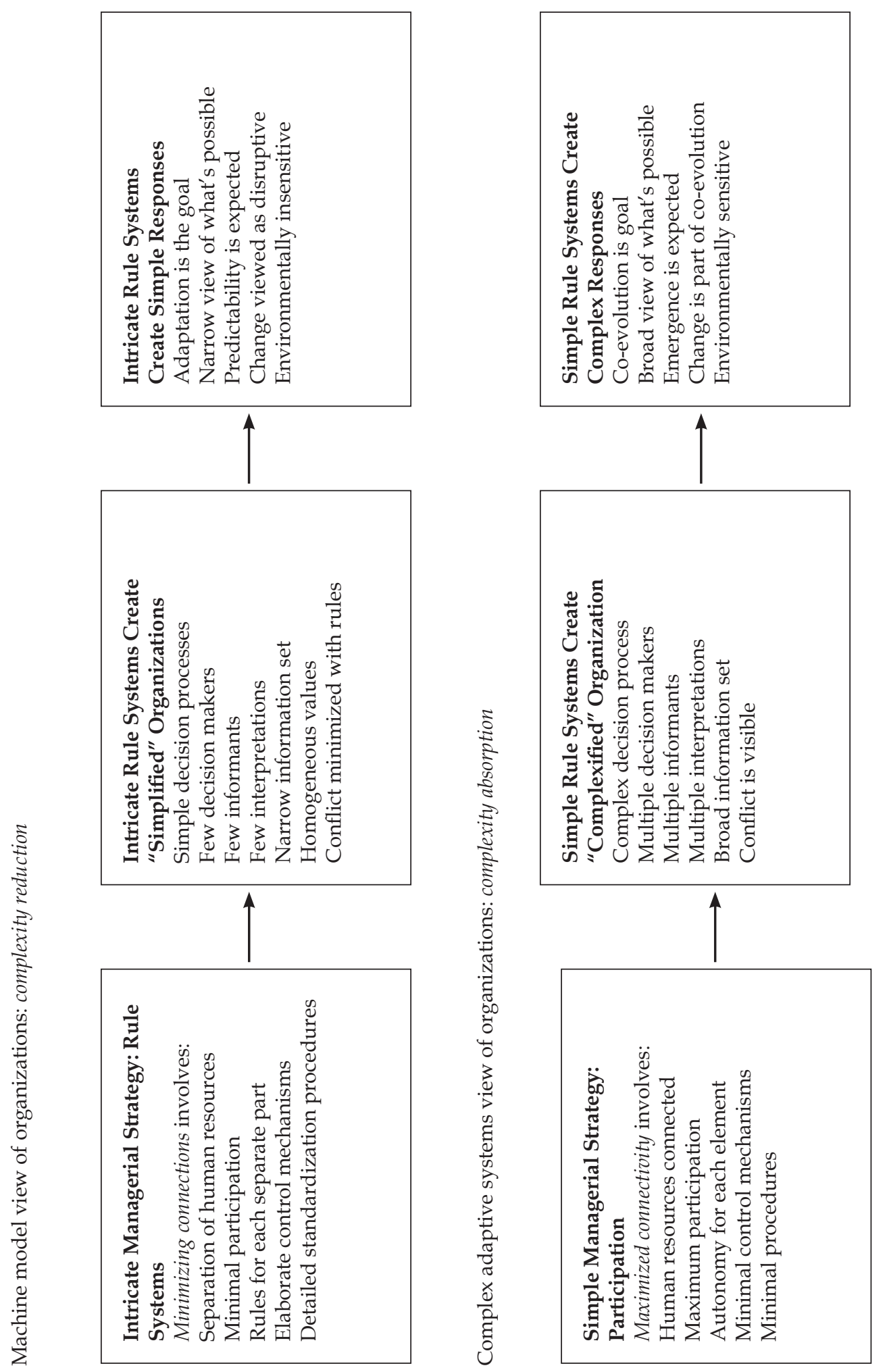


may be called on to verify that the rules have been followed, few (if any) are allowed to question the validity of the rules themselves. Thus, over time the system can become non-adaptive because only one agent (the rule system) is involved in the interpretation of data, one agent "makes sense" of the environment, and one agent decides what shall be done. Even if a top management team is allowed to modify the rule system, the result is most likely to be a modest, incremental modification. Even with input from a top management team the system's knowledge and values will remain narrow and static because of the limited number and variety of viewpoints. Such a simplified organization system then can do little else but create simple, incremental responses to its potentially rapidly changing and complex environment.

In contrast, the complex adaptive systems view of organizations, also presented in figure 1, proposes the use of a simple rule-participation-as a way of maximizing connectivity. From this view, agents are more connected and less separated from each other in the organization, there is greatly enhanced participation in decision making, each element in the system has more autonomy, and there is less emphasis on standardizing control procedures. This simple rule creates a messier organization, a "complexified" organization where the decision processes themselves are complex, involving multiple decision makers and multiple informants. This in turn will allow for multiple interpretations of problems, the use of a broad information set and consideration of heterogeneous values. The simple rule of participation makes visible conflicting views that are present. The benefit of creating this kind of organizational "mess" is that the organization is more likely to recognize or create a successful adaptation in response to environmental complexity. In such an organization change is not seen as disruptive, but rather as part of co-evolution. Co-evolution becomes normal and expected in contrast to the predictability expected in a machine system. These organizations are also likely to develop greater environmental sensitivity.

Organizations need to develop larger repertoires of potentially adaptive behavior because the problems they face in complex environments are likely to be novel, multi-faceted, complex problems. Larger, more complex behavioral repertoires increase the chances of developing an adaptation that is part of a successful co-evolution. Moreover, adaptive behaviors will likely have to be developed quickly because of the nature of high velocity environments (Eisenhardt, 1989). As Locke et al. (1997) note, the organization that knows the most, knows it fastest, and can use it most readily will be in the best position to succeed. Complex and timely adaptive behaviors can best be achieved from organizational processes that are free of elaborate, restrictive rules and control features, because elaborate rules and control systems restrict both creative thinking and action. Instead the organization needs simple, flexible rule systems which both generate large behavioral repertoires and can be applied quickly. Wheatley and Kelner-Rogers (1996) speak to the value of using simple rules:

Systems become healthier as they open to include greater variety. When diversity abounds in an environment of freedom, the result is strong and resilient systems ... We can support systems in being resilient by encouraging them to exercise their freedom to explore new connections and new information. A healthy system uses its freedom to explore its identity. It is free to look outward, to bring in others, to contemplate new information. These explorations lead the system into new and different ways of being. (p. 101) 


\section{Participation as a Useful Complexifying Mechanism}

Interestingly there is a well-recognized (if not well-used) management practice that will complexify everyday life by enriching connections among people: participation in decision making. Here we use the term participation to mean joint decision making (Locke and Schweiger, 1979) or influence-sharing between hierarchical superiors and subordinates (Locke et al., 1997; Wagner and Gooding, 1987). We are not talking about delegation, which is the process by which the manager transfers authority to a subordinate (Leana, 1987). Participation is a topic that has a long and rich history in the study of organizations. For many years researchers have believed participation to be a motivational tool for improving performance, although empirical results have yet to strongly support that assertion, particularly at the individual and group level. In addition to looking at participation and motivation, numerous studies have linked participation to organizational commitment and job satisfaction (Connor, 1992; Locke and Schweiger, 1979; Miller and Monge, 1986; Sagie, 1994); however, findings regarding the link to performance have been inconsistent (Cotton et al., 1988; Locke et al., 1997; Schweiger and Leana, 1986).

Many of these studies have focused on participation and its effects at the individual or small group level, but we are viewing participation the organizational level - as a property of the system. At the organizational level, participation has been viewed, conceptually, as a management tool for facilitating communication, building commitment, and improving implementation of decisions (Locke and Schweiger, 1979), although it is also recognized for being time consuming and "messy." More recently Locke et al. (1997) conclude that the major benefit of participation is as a mechanism for information exchange and knowledge transfer. As noted above, we argue that participation goes beyond knowledge transfer and that the web of relationships developed by participation becomes the instrument for creative thinking, transformation, and ultimately successful adaptation. In complex adaptive systems, participation can be the mechanism for intentional internal complexity achieved as a result of applying a simple rule (i.e. use participation). When done well participative decision making changes the "traditional" role of manager as an all-knowing overseer because it reduces the manager's capacity to establish and maintain control. But this also means that the manager is less likely to be overloaded with the need to know everything, the need to coordinate and organize everything. In a complex systems sense participation is a way of encouraging self-organizing.

Self-organizing occurs when connections and interactions among group members produce coherent behavior, even in the absence of a hierarchy which in the machine model is used to ensure order. These patterns of coherent behavior can be spontaneous, that is, not decreed or designed by any individual. Such spontaneous patterns may disappear, or they may have a long lasting effect. In the latter case an evolution has occurred. Note that spontaneous self-organizing is not a far-fetched idea. Informal groups of managers and employees form networks and no central authority organizes them. Yet these informal networks behave in a controlled way and are often critical to the organization's well being (Stacey, 1992). Thus, self organizing is about developing new, coherent patterns of behavior.

The process of participation is a mechanism for self-organizing. Participation makes connections richer and denser inside an organization because it brings peo- 
ple together and presents opportunities to exchange and process information (Locke et al., 1997), but then also to learn more about the system, and to create new meanings for organizational members. Participation, as a social process, creates a platform such that self-organizing becomes an expression of organizational learning and sense making. Putting people together and setting them free to solve problems can have profound benefits for an organization, even if in the short run, things seem unclear, messy, and slow. Wheatley and Kelner-Rogers (1996, p. 71) describe this mess.

From such local, autonomous, and messy negotiations, something large, complex, and useful emerges. Individual freedom leads to global stability. Through messy parallel activities, life organizes its effectiveness. It looks like a mess. It is a mess. And from the mess, a system appears that works.

The challenge for managers is to achieve the kind of balance that will allow them to move quickly yet seek valuable input, to understand the past but move beyond it, and to recognize when to let go of outmoded practices. This challenge is particularly interesting because while many managers and organizations pay lip service to participative practices (witness the enthusiasm for teams), it is difficult to make participation work (witness the declining enthusiasm for teams).

Managers often view participative processes as problematic, not only because they can be slow and messy, but also because they lead to conflict (Duchon et al., 1998). Pursuing participation can be frustrating. Decisions take longer, information surfaces that is of questionable quality, and the various interpretations of what things mean is troubling. Weick describes these frustrations as follows:

... meetings that are well suited to address ambiguity tend to be messy. Too many cues and too many interpretations and too little closure persist for too long when people try to discover what they really ought to be addressing and what kinds of understanding they need to negotiate. Such gatherings are not for the faint of heart. (Weick, 1995, p. 186)

Yet it is precisely the conflict of opposing views and interpretations that is needed for first making sense and then making good decisions. Eisenhardt et al. (1997) found that top management teams with the highest levels of conflict were leading the highest performing firms, allowing them to conclude that "conflict over issues is not only likely within top-management teams but also valuable" (1997, p. 84). Moreover, participative processes reinforce a sense of interdependence, of being connected and being part of a larger system. Participative processes take advantage of the web of relationships where everything affects everything else (Capra, 1996).

\section{Research Supporting the Argument}

We have been studying participation in strategic decision making, how it occurs, and what difference it makes for several years. Based on our view of organizations as complex systems, we have been trying to understand the role of participation and its potential as a mechanism for enhancing connection and self-organizing patterns. 
In one study we examined an organization's predisposition to engage in strategic decision making in an effort to learn how the predisposition affects participation. We also noticed that some organizations are more environmentally sensitive and that this sensitivity may be associated with internal complexity. Thus, we conducted a further study of environmental sensitivity and its relationship to participation. From these studies and others we have begun to build a knowledge base of conditions in which enhancing connections through participation can be viable and how connections can be managed for maximum benefit.

\section{Participation and Predisposition}

There are several issues regarding participation that we sought to understand, such as the barriers to participation (i.e. what are the factors that affect the degree to which participation occurs). We were drawn to the arguments posed by institutional theorists that organizations are predisposed towards some behaviors more so than others (DiMaggio and Powell, 1983; Meyer and Rowan, 1977). The argument is based in part on the notion that institutions "consist of cognitive, normative, and regulative structures and activities that provide stability and meaning to social behavior" (Scott, 1995, p. 33). These structures and activities that give meaning predispose organizations to behave in certain ways. In one study of more than 50 organizations we observed participation in strategic decision making to be affected by an organization's predisposition (Ashmos et al., 1998). We based our conceptualization and measurement of predisposition on the classic works of institutional theorists such as Veblen (1919), who defines institutions as settled habits of thought common to the generality of human beings, and Selznick (1957) who describes the process of institutionalization as something that happens to an organization over time, reflecting the organization's own distinctive history. More recently Thalen and Steinmo (1992) describe institutions as including both formal structures and informal rules and procedures that structure conduct. Scott (1995) describes the most dominant institutional view as focusing on how the regulative processes of the institution, embodied in rules and attention to rules, constrain and regularize behavior. March and Olsen (1989, p. 23) refer to this element that contributes to our notion of predisposition:

To describe behavior as driven by rules is to see action as a matching of a situation to the demands of a position. Rules define relationships among roles in terms of what an incumbent of one role owes to incumbents of other roles.

We had the opportunity to examine predisposition in a study of organizations in the hyper-turbulent health care environment, an industry whose entire structure is rapidly changing. We believed that past performance in addition to an organization's attention to rules and procedures "predispose" organizations to behave in certain predictable patterns. Success in the past would predispose the organization to repeat its past behavior in spite of the nature of the specific issue to be decided, and highly bureaucratized organizations are predisposed to follow rules. We found that in hospitals predisposed towards rule orientation and formalization, there was much less participation in strategic decision making of key internal stakeholder groups than in 
hospitals that did not share this predisposition. We observed that hospitals' past performance affected the amount of participation, as well. The organization's predisposition was a more powerful predictor of participation than was how the decision makers perceived the issue (as a threat or opportunity). We inferred that organizations are predisposed one way or the other, because of past performance or past attention to rules and formality, towards using or not using participation. This predisposition, then, is a powerful inertia-type force that appears to limit future managerial behavior, and thereby the degree to which connectivity can occur in organizations. From the view of organizations as complex adaptive systems this finding is important because it suggests that predisposition powerfully limits the nature of organizations' co-evolutionary processes. In stable environments such limits may not much matter, but in changing and unstable environments such limits are problematic, even dangerous to the organization's long term viability.

\section{Environmental Sensitivity and Participation}

In thinking about how predisposition is a barrier to participation we sought to understand more about the relationship between an organization's environmental posture (whether it is environmentally sensitive or not) and the amount of participation that occurs in the organization. We were drawn to the idea that organizations differ in terms of their environmental sensitivity, and those that are environmentally sensitive are likely ones that have overcome the inertia of predisposition. This argument was based on the notion that institutional environments change and that organizations respond to these changes by altering their response patterns (Alexander and D'Aunno, 1990). In complex systems terms this organization- environmental relationship is thought of as "co-evolutionary" (Capra, 1996). Therefore, another study grew out of the belief that one way for organizations to overcome predisposition (institutional theorists might call it "deinstitutionalization") is to be environmentally sensitive, or environmentally aware. We wanted to look at the differences in the internal make-up of environmentally sensitive and insensitive organizations to see if we could identify differences in participation patterns. In this study (Ashmos et al., 1996) we looked closely at 21 organizations (a subset from the larger set of the first study) that we characterized as either "environmentally sensitive" or "environmentally insensitive," depending on how managers described their organization's eagerness to make changes in response to changing conditions in the environment. Environmentally sensitive hospitals were those that saw change occurring in their environment and responded consistently with organizational changes and adaptations. That is, they were engaged in co-evolutionary behavior. The environmentally insensitive hospitals were those which had no consistent approach to change. These two groups of hospitals revealed significant differences in the internal patterns of participation. Environmentally sensitive hospitals were much more complex internally. Participation was greater and the patterns of participation were more complex (more connections) than those in the environmentally insensitive hospitals. The environmentally sensitive hospitals also had more complex sets of goals, more complicated strategies and more structural complexity. Note that in these environmentally sensitive hospitals participation was one of several factors contributing to internal complexity. When or- 
ganizations are sensitive to the turbulence in their environment they appear to take intentional steps to respond to this turbulence. We concluded that organizations that see environmental complexity and respond to it aggressively are also internally complex: more and different goals, more complicated strategies, complex structures, and particularly more participation.

\section{Internal Complexity, Participation, and Performance}

Our finding that more environmentally sensitive organizations were in fact more complicated internally (Ashmos et al., 1996) led us to the question of what difference does this internal make-up have on firm financial performance. In a small sample study of eight organizations we compared the financial performance of four organizations whose internal make-up was considerably more complex, or "messy" than the other four organizations (Ashmos et al., 2000). These internally complex organizations had more and different goals, more complicated strategies, complex structures and much more participation at all levels in the organization. Using numerous measures of financial performance we observed that the more internally complex organizations significantly outperformed those organizations that were less complex internally.

In a study of registered nurse participation in nursing home decision making, Anderson and McDaniel (1999) found that nursing homes with the most improvement in resident outcomes had greater RN participation in decision making that did homes with the least improvements. The results of this study suggested that nursing homes that want to improve quality often complexify their systems through increased participation. This is a process that can be used to manipulate important control parameters that enhance the ability of a system to self-organize (Mainzer, 1997). Thus we found in our empirical work, that several different indicators of organizational performance are potentially enhanced when complexification takes place. This is consistent with our present understanding of organizations as complex adaptive systems.

\section{Three Issues for Managing Participation}

Based on our empirical studies as well as previous work on participation (Ashmos and McDaniel, 1991,1996) we can make three statements about how to better manage participation. First, any effort to complexify the organization and enhance connections is heavily influenced by the things that have happened in the past, by the habits and over-learned responses of the organization (its predisposition). Second, we see that participation is part of a larger overall complexifying approach that characterizes some, but not all, organizations. Finally, this overall complexifying approach appears to have pay-offs for the organization.

The results from our studies suggest that participation must be considered in light of an organization's predisposition and its environmental sensitivity. Predisposition refers to institutional forces such as past performance, reliance on rules, and rigidity of roles. Environmental sensitivity refers to an organization's willingness to respond quickly to perceived environmental changes. Figure 2 shows how the three variables seem to be related. 


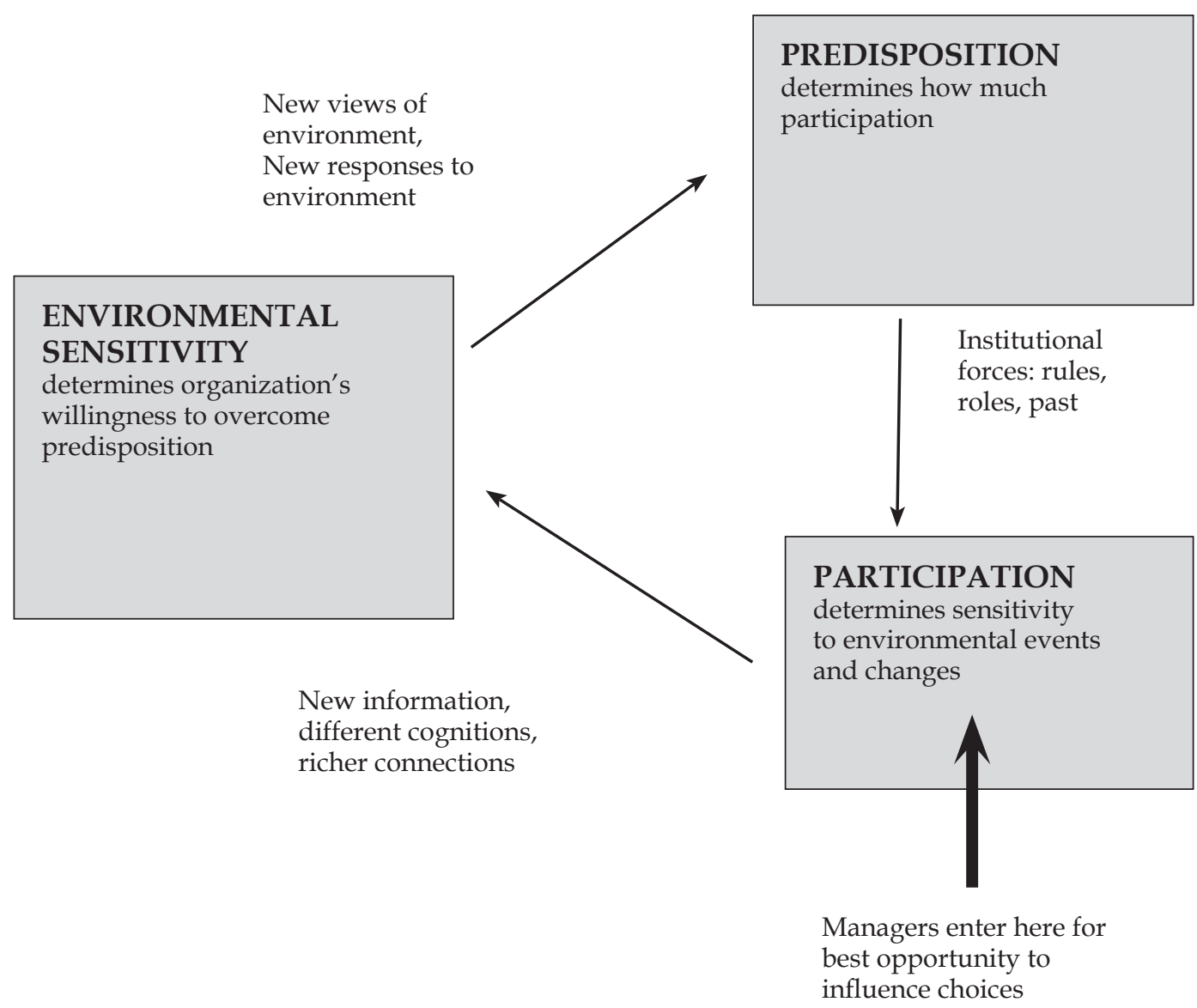

Figure 2. The predisposition/participation/environmental sensitivity loop

Organizational predisposition affects how much participation occurs in organizations because of institutional forces that exert continual pressure on organizations to do things a certain way. The amount of participation affects how sensitive organizations are to their environment because multiple participants create multiple perspectives which usually lead to new and different ways of viewing the environment. Environmental sensitivity affects predisposition because organizations that are environmentally sensitive are complex and have the ability to alter the organization's predisposition. Figure 2 presents a kind of continuous, self-reinforcing loop. We contend the best opportunity for managers to enter the loop and modify organization activities and success is through participation. Changing participation ultimately changes predisposition.

\section{Conclusion}

Leaders in the management community such as Herb Kelleher of Southwest Airlines (Kelleher, 1997), Dee Hock of VISA (Hock, 1999), and others have challenged 
managers to re-think their approaches to leading organizations. Kelleher (1997) writes:

A financial analyst once asked me if I was afraid of losing control of our organization. I told him, "I've never had control and I never wanted it. If you create an environment where the people truly participate, you don't control." (Kelleher, 1997, p. 21)

Thinking about organizations as complex adaptive systems provides a new way of understanding the challenges to managers posed by Kelleher and others. In this paper we have used this emerging paradigm - complex adaptive systems - in order to argue what may seem to conventional organizational thinkers as a paradox. Rather than relying on a complex rule system to reduce the complexity of the external environment, we contend that organizations are better advised to absorb that complexity, and such absorption is best accomplished by rigorously applying a simple rule: use participative decision making. Participative decision making will enhance and make denser the organization's web of relationships, and at the same time set free a broad range of ideas and strategies which can lead to the organization developing a larger behavioral repertoire. These factors may make the management of participation messy, but in the long run the results will be worth the effort.

While some of our arguments may seem counter-intuitive to conventional management practice, we offer research to support our contentions. Essentially this research shows that the inertia of machine-model organizations is difficult to overcome, but those organizations which manage to absorb complexity through participative systems in fact are more successful.

Organizations develop habits that are hard to break. For a variety of reasons organizations become predisposed to do things a certain way. These habits can lead to rigid behavior in a world that is fluid and dynamic. However, predisposition can be managed by knowing that participation in decision making creates a multitude of rich connections that help organizations survive because participation affects the degree to which organizations develop sensitivities to their environment. This sensitivity in turn affects the organization's predisposition. This may seem like a cycle that can't be broken, but our research suggests that participation is the mechanism for entering this cycle. It is a mechanism that both enriches existing connections and creates new connections in organizations.

Participation complicates things. Often when participation occurs, disorder becomes more observable, conflict is more visible and, initially, confusion abounds. By traditional standards of managerial efficiency and effectiveness participation creates a mess for managers. But it is a mess that organizations can't afford to avoid. Participation allows opportunities for multiple interpretations of environmental events and can also help surface conflict, the resolution of which can reduce internal and external ambiguities. Resolving conflict can help people discover and agree on where they're going and how they'll get there. The process of making and sustaining connections through participation allows the organization to self-organize, to re-energize, and to co-evolve in ways that are more likely to lead to organizational success. 


\section{References}

Adler, P. A. (1999). “Building better bureaucracies." Academy of Management Executive, 13, 4, 36-47.

Alexander, J. A. and D'Aunno T. (1990). “Transformation of institutional environments: perspectives on the corporatization of U.S. healthcare." In Mick, S. (Ed.), Innovations in Health Care Delivery: Insights for Organization Theory. San Francisco: Jossey-Bass, 53-85.

Anderson, P. (1999). “Complexity theory and organization science." Organization Science, 10, 3, 216-32.

Anderson, R. A. and McDaniel R. R. (1999). “RN participation in organizational decision making and improvements in resident outcomes." Health Care Management Review, 24, 1, 7-16.

Anderson, R. A. and McDaniel R. R. (2000). "Managing health care organizations: Where professionalism meets complexity science." Health Care Management Review, 25, 1, 83-92.

Ashmos, D. P. and McDaniel, R. R. (1991). "Physician participation in hospital strategic decision making: the effects of hospital strategy and decision content." Health Services Research, 26, 3, 375-401.

Ashmos, D. P. and McDaniel, R. R. (1996). "Understanding the participation of critical task specialists in strategic decision making." Decision Sciences, 27, 1, 103-21.

Ashmos, D. P., McDaniel, R. R. and Duchon D. (1990). “Differences in perception of strategic decision making processes: the case of physicians and administrators." Journal of Applied Behavioral Science, 26, 2, 201-18.

Ashmos, D. P., Duchon, D., Hauge, F. and McDaniel, R. R. (1996). “Internal complexity and environmental sensitivity in hospitals." Hospital \& Health Services Administration, 41, 4, 535-55.

Ashmos, D. P., Duchon, D. and McDaniel, R. R. (1998). “Participation in strategic decision making: the role of organizational predisposition and issue interpretation." Decision Sciences, 27, 1, 103-21.

Ashmos, D. P., Duchon, D. and McDaniel, R. R. (2000). “Organizational responses to complexity: the effect on organizational performance." Journal of Change Management, 13, 6, 577-94.

Axelrod, R. and Cohen, M. D. (1999). Harnessing Complexity: Organizational Implications of a Scientific Frontier. New York: The Free Press.

Boisot, M. and Child, J. (1999). "Organizations as adaptive systems in complex environments: the case of China." Organization Science, 20, 3, 237-52.

Brown, S. L. and Eisenhardt, K. M. (1998). Competing on the Edge. Boston: Harvard Business School Press.

Burns, T. and Stalker, G. M. (1961). The Management of Innovation. London: Tavistock.

Capra, F. (1996). The Web of Life. New York: Anchor Books Doubleday.

Casti, J. L. (1995). Complexification: Explaining a Paradoxical World Through the Science of Surprise. New York: HarperCollins.

Connor, P. E. (1992). “Decision making participation patterns: the role of organizational context." Academy of Management Journal, 35, 218-31.

Cotton, J. L., Vollrath, D. A., Froggatt, K. L., Lengnick-Hall, M. L. and Jennings, K. R. (1988). "Employee participation: diverse forms and different outcomes." Academy of Management Review, 13, 8-22. 
Daft, R. L. and Marcic, D. (1998). Understanding Management. Orlando: Dreyden Press.

DiMaggio, P. J. and Powell, W. W. (1983). "State expansion and organizational fields." In Hall, R. H. and Quinn, R. E. (eds.), Organizational Theory \& Public Policy. Beverly Hills: Sage Publications.

Duchon, D., Ashmos, D. P. and Nathan, M. (1998). "Making sense with teams in the new world of management." In Bullock, M. and Beyerlin, M. (eds.), Advances in Interdisciplinary Studies of Work Teams. Greenwich, CT: JAI Press.

Eisenhardt, K. L. (1989). "Making fast strategic decisions in high velocity environments." Academy of Management Journal, 14, 532-50.

Eisenhardt, K. M., Kahwajy, J. L. and Bourgeois, L. J. (1997). “How management teams can have a good fight." Harvard Business Review, 75, 4, July-August, 77-85.

Handy, C. (1994). The Age Of Paradox. Boston: Harvard Business School Press.

Hock, D. (1999). Birth of the Chaordic Age. San Francisco: Berrett-Koehler.

Holland, J. H. (1998). Emergence: From Chaos to Order. Reading, MA: Addison-Wesley.

Kauffman, S. (1995). At Home in the Universe. Oxford: Oxford University Press.

Kelleher, H. (1997). “A culture of commitment." Leader to Leader, 20-4.

Locke, C. (1987). "Power relinquishment versus power sharing: theoretical clarification and empirical comparison of delegation and participation." Journal of Applied Psychology, 72, 2.

Locke, E. and Schweiger, D. (1979). "Participation in decision making: one more look." In Staw, B. M. (ed.), Research in Organizational Behavior, Vol. 1. Greenwich, CT: JM Press, 265-339.

Locke, E., Alavi, M. and Wagner, J. A. III (1997). "Participation in decision making: an information exchange perspective." In Ferris, G. R. (Ed.), Research in Personnel and Human Resource Management, Vol. 15. Greenwich, CT: JAI Press, 293-331.

Mainzer, K. (1997). Thinking in Complexity: The Dynamics of Matter, Mind and Mankind, 3rd ed. New York: Springer.

March, J. and Olsen J. P. (1989). Rediscovering Institutions: The Organizational Basis of Politics. New York: John Wiley.

McDaniel, R. R. (1997). "Strategic leadership: a view from quantum and chaos theories." In Duncan, J., Swayne, L. and Ginter, P. (eds.), Handbook of Healthcare Management. Oxford: Blackwell Publishers, 339-67.

Meyer, J. W. and Rowan, B. (1977). “Institutional organizations: formal structure as myth and ceremony." American Journal of Sociology, 83, Sept, 340-63.

Miller, K. I. and Monge, P. R. (1986). "Participation, satisfaction, and productivity: a metaanalytic review." Academy of Management Journal, 29, 727-53.

Morgan, G. (1998). Images of Organization: The Executive Edition. San Francisco: Berrett-Koehler.

Sagie, A. (1994). "Participative decision making and performance: a moderator analysis." Journal of Applied Behavioral Science, 30, 2, 227-46.

Schweiger D. M. and Leana, C. R. (1986). "Participation in decision making." In Locke, E. A. (Ed.), Generalizing From Laboratory to Field Settings. Lexington, MA: D.C. Health, 147-66.

Scott, R. W. (1995). Institutions and Organizations. Thousand Oaks, CA: Sage Publications.

Selznick, P. (1957). Leadership and Administration. New York: Harper \& Row.

Stacey, R. D. (1992). Managing the Unknowable. San Francisco: Jossey-Bass. 
Stacey, R. D. (1995). “The science of complexity: an alternative perspective for strategic change processes." Strategic Management Journal, 16, 6, 377-495.

Thalen, K. and Steinmo, S. (1992). "Historical institutionalism in comparative politics." In Steinmo, S., Thalen, K. and Meyer, J. (eds.), Structuring Politics: Historical Institutionalism in Comparative Analysis. Cambridge, UK: Cambridge University Press.

Veblen T. (1919). The Place of Science in Modern Civilization and Other Essays. New York: Huebsch.

Wagner, J. A. and Gooding, R. Z. (1987). “Shared influence and organizations behavior: a meta-analysis of situational variables expected to moderate participation-outcome relationships." Academy of Management Journal, 30, 3, 524-41.

Weick, K. (1979). The Social Psychology of Organizing. New York: Random House.

Weick, K. (1995). Sensemaking in Organizations. Thousand Oaks: Sage Publications.

Wheatley, M. (1992). Leadership and the New Science. San Francisco: Berrett-Koehler.

Wheatley, M. and Kelner-Rogers, M. (1996). A Simpler Way. San Francisco: Berrett-Koehler. 